\title{
Exigências nutricionais da grápia em Argissolo Vermelho distrófico arênico: (II) Efeito da adubação NPK no teor de nutrientes nos tecidos
}

\author{
Nutritional demand of grápia in Paleaudalf soil: (II) Effect of NPK fertilization on content of nutrients in the \\ tissues
}

\author{
Fernando Teixeira Nicoloso ${ }^{\mathrm{I}}$ Marco Aurélio de Freitas Fogaça ${ }^{\mathrm{II}}$ Flávio Zancheti ${ }^{\mathrm{II}}$ \\ Roni Paulo Fortunato ${ }^{\mathrm{IV}}$ Evandro Luiz Missiov
}

\section{RESUMO}

A grápia (Apuleia leiocarpa (Vog.) Macbride) é uma espécie florestal nativa de ampla utilidade na indústria madeireira, motivo pelo qual, atualmente, encontra-se em processo de extinção. Em trabalho prévio, utilizando-se um Argissolo Vermelho distrófico arênico, foi demonstrado que o crescimento de plantas jovens de grápia respondeu à adubação de $N$, P e K com dose de máxima eficiência técnica estimada em, respectivamente, 70,80 e $80 \mathrm{mg} \mathrm{kg}^{-1}$. No presente trabalho, objetivou-se caracterizar o efeito da adubação NPK nos teores de macronutrientes e micronutrientes dos tecidos de plantas de grápia. Em condições de casa de vegetação, foram realizados 27 tratamentos de adubação em esquema trifatorial completo (3x3x3), representados por três níveis $\left(0,40\right.$ e $\left.80 \mathrm{mg} \mathrm{kg}^{-1}\right)$ de $\mathrm{N}$, de $P$ e de K. A parcela experimental foi constituída de um vaso com $3,5 \mathrm{~kg}$ de Argissolo Vermelho distrófico arênico e duas plantas. Aos 140 dias após a emergência das plantas, avaliouse o crescimento e os teores de $\mathrm{N}, \mathrm{P}, \mathrm{K}, \mathrm{Ca}, \mathrm{Mg}, \mathrm{Cu}, \mathrm{Zn}, \mathrm{Fe}$ e $\mathrm{Mn}$ nas folhas, no caule e nas raízes da grápia. Os resultados sugerem que os teores adequados de nutrientes nas folhas de plantas jovens de grápia, para se obter de 80 a 100\% da produção de biomassa, sejam: $N=2,5$ a 3,0\%; $P=0,1$ a $0,18 \%$, $K=1,6$ a 2,1\%, Ca=0,60 a 0,75\%, $\mathrm{Mg}=0,2$ a 0,3\%; $\mathrm{Cu}=1,5$ a $2,5 \mathrm{mg} \mathrm{kg}, \mathrm{Zn}=50$ a $85 \mathrm{mg} \mathrm{kg}$, Fe=100 a $150 \mathrm{mg} \mathrm{kg}^{-1} \mathrm{e}$ $\mathrm{Mn}=250$ a $400 \mathrm{mg} \mathrm{kg}^{-1}$.

Palavras-chave: espécie florestal, macronutriente, micronutriente, Apuleia leiocarpa, nutrição mineral.

\section{ABSTRACT}

Grápia (Apuleia leiocarpa (Vog.) Macbride) is a Brazilian forest species with great interest for timber-trade, and

\begin{abstract}
nowadays due to deforestation, it has been considered in extinction process. In the previous paper, it was shown that the NPK fertilization, respectively at 70, 80 and $80 \mathrm{mg} \mathrm{kg}^{-1}$ of a Paleudalf soil, significantly increased the growth of young plants of grápia. The present study is aimed at characterizing the effects of the NPK fertilization on macronutrient and micronutrient contents in the tissues of grápia. At glasshouse conditions, 27 fertilization treatments were used in a complete trifactorial scheme $(3 \times 3 \times 3)$, represented by the combination of three levels $\left(0,40\right.$ and $\left.80 \mathrm{mg} \mathrm{kg}^{-1}\right)$ of $N$, of $P$ and of $K$. As experimental unit, pots with $3.5 \mathrm{~kg}$ of a Paleudalf soil and two plants were used. At 140 days after plant emergence, plant growth and the contents of $\mathrm{N}, \mathrm{P}, \mathrm{K}, \mathrm{Ca}, \mathrm{Mg}, \mathrm{Cu}, \mathrm{Zn}, \mathrm{Fe}$, and $\mathrm{Mn}$ in leaves, stem and roots were evaluated. The data suggest that the adequate nutrient contents in leaves of young plants of grápia, envision to obtain 80 to $100 \%$ of biomass production, were: $N=2,5$ a 3,0\%; $P=0,1$ a 0,18\%, $K=1,6$ a 2,1\%, Ca=0,60 a 0,75\%, $\mathrm{Mg}=0,2$ a 0,3\%; $\mathrm{Cu}=1,5$ a 2,5 mg kg-1, $\mathrm{Zn}=50$ a $85 \mathrm{mg} \mathrm{kg}^{-1}, \mathrm{Fe}=100$ a $150 \mathrm{mg} \mathrm{kg}^{-1}$ e $\mathrm{Mn}=250$ a $400 \mathrm{mg} \mathrm{kg}^{-1}$.
\end{abstract}

Key words: forest species, macronutrient, micronutrient, Apuleia leiocarpa, mineral nutrition.

\section{INTRODUÇÃO}

Nas últimas décadas, com o crescimento populacional e a expansão geográfica da agropecuária, muitas áreas de floresta nativa foram destruídas, fazendo com que inúmeras espécies vegetais se encontrem ameaçadas de extinção (SEMA, 2006). Dentre essas, salienta-se a grápia (Apuleia leiocarpa

\footnotetext{
IDepartamento de Biologia, Universidade Federal de Santa Maria (UFSM), 97105-900, Santa Maria, RS, Brasil. Autor para correspondência. E-mail: ftnicoloso@yahoo.com.

IIPrograma de Pós-graduação em Agronomia, UFSM, Santa Maria, RS, Brasil.

IIIPrefeitura Municipal de Seara, SC, Brasil.

IvSLC Agrícola Ltda., Luziânia, GO, Brasil.

`Fundação Estadual de Pesquisa Agropecuária (FEPAGRO), Júlio de Castilhos, RS, Brasil.
} 
(Vog.) Macbride), uma leguminosa que originalmente possuía ampla distribuição geográfica, presente desde alguns Estados do Nordeste brasileiro até a Argentina e o Uruguai (RIZZINI, 1971). No Rio Grande do Sul, a grápia destacou-se como uma das espécies particularmente dispersas pela ampla bacia do Rio Jacuí (REITZ et al., 1988), sendo que, atualmente, apresentase bastante desuniforme devido à devastação intensa das matas do Estado (SEMA, 2006).

A caracterização do comportamento nutricional da grápia é importante para a elaboração de projetos de reflorestamento. Nesse contexto, vários trabalhos têm sido realizados visando a elucidar as suas necessidades nutricionais (NICOLOSO et al., 1999, 2001, 2005; MISSIO et al., 2004; FORTUNATO \& NICOLOSO, 2004; MISSIO \& NICOLOSO, 2005).

Estudando as exigências nutricionais de mudas de grápia pela técnica do nutriente faltante, em Argissolo Vermelho distrófico arênico, NICOLOSO et al. (1999) observaram que a altura da planta, o número de nós do caule, o número de folhas, o comprimento do sistema radicular, a matéria seca da planta e o teor de nutrientes nos tecidos da planta diminuíram acentuadamente pela omissão isolada de $\mathrm{P}, \mathrm{S}, \mathrm{N}$ e K na adubação, tanto no horizonte A como no B do solo.

Para o eucalipto, a fertilização nitrogenada tem trazido respostas significativas da planta nos seus estágios iniciais de crescimento ou a campo, após o transplantio das mudas (NOVAIS et al., 1990). Em grápia, NICOLOSO et al. (1999) verificaram que a omissão de $\mathrm{N}$ reduziu drasticamente o crescimento das mudas cultivadas em Argissolo Vermelho distrófico arênico. Em estudo posterior, também utilizando o mesmo solo e as mesmas condições experimentais, NICOLOSO et al. (2005) demonstraram que a razão adequada entre as fontes de $\mathrm{N}_{-} \mathrm{NO}_{3}: \mathrm{N}^{-\mathrm{NH}_{4}^{+}}$na adubação para a produção de mudas de grápia não deve ultrapassar, respectivamente, o valor de 4:1.

A baixa disponibilidade de P, em cerca de 80\% dos solos da América Latina Tropical, é uma das limitações mais comuns à produção agropecuária (SANCHEZ \& SALINAS, 1981). O aproveitamento do $\mathrm{P}$ oriundo do solo é influenciado por diferenças genotípicas das espécies vegetais, as quais se relacionam à capacidade de absorção e à eficiência de utilização deste nutriente (RESENDE et al., 2000; LUCA et al. 2002; PAOLI et al., 2005). Em solos bastante deficientes em $\mathrm{P}$, a baixa absorção pela planta pode ainda prejudicar o metabolismo de outros nutrientes nos tecidos, principalmente de nitrogênio, devido à exigência adicional de energia para redução do $\mathrm{N}^{-\mathrm{NO}_{3}}{ }_{3}^{-}$ (MARSCHNER, 1995).
Para mudas de Eucalyptus grandis cultivadas em amostras de 13 solos de diferentes procedências, PREZOTTI (1985) observou respostas significativas à aplicação de potássio na maioria deles, sendo que o teor de K disponível no solo era, em geral, superior a 30 $\mathrm{mg} \mathrm{kg}^{-1}$. Entretanto, para NOVAIS et al. (1990), apesar das respostas positivas observadas em relação à aplicação de K, tem se verificado que elas são relativamente pequenas quando comparadas àquelas geralmente encontradas para a adição de fósforo ou de enxofre. Além disso, esses autores sugerem que, ao contrário do que ocorre com o fósforo, o nível crítico de potássio no solo, para o crescimento do eucalipto, aumenta com a idade da planta.

Em trabalho prévio, NICOLOSO et al. (2001) constataram que a máxima eficiência técnica estimada da adubação fosfatada e potássica na produção de biomassa de plantas de grápia ficou acima da maior dose utilizada, $80 \mathrm{mg} \mathrm{kg}^{-1}$, e, para a adubação nitrogenada, foi de $70 \mathrm{mg} \mathrm{kg}^{-1}$. No presente trabalho, utilizando a mesma biomassa de plantas de grápia obtidas por NICOLOSO et al. (2001), objetivou-se caracterizar os efeitos da adubação NPK nos teores dos nutrientes N, P, K, Ca, Mg, Cu, Zn, Fe e Mn nos tecidos de raízes, caule e folhas.

\section{MATERIAL E MÉTODOS}

As plantas de grápia (Apuleia leiocarpa (Vog.) Macbride) foram originadas de sementes tratadas quimicamente com $\mathrm{H}_{2} \mathrm{SO}_{4}$ concentrado, segundo método descrito por NICOLOSO et al. (1997). $\mathrm{O}$ solo utilizado no experimento foi coletado de 0 a 0,65m de profundidade do horizonte A de um Argissolo Vermelho distrófico arênico no município de Santa Maria, RS. Os dados das análises físicas e químicas desse solo foram apresentados previamente por NICOLOSO et al. (2001). O experimento foi conduzido na casa de vegetação do Departamento de Fitotecnia do Centro de Ciências Rurais, na Universidade Federal de Santa Maria, RS.

Foram avaliados 27 tratamentos de adubação em esquema trifatorial completo (3x3x3), representados por três doses $\left(0,40,80 \mathrm{mg} \mathrm{kg}^{-1}\right)$ de $\mathrm{N}$, de $\mathrm{P}$ e de $\mathrm{K}$. O delineamento experimental usado foi de tratamentos inteiramente casualizados, com cinco repetições. A parcela experimental foi constituída de um vaso com $3,5 \mathrm{~kg}$ de terra fina seca ao ar e de duas plantas, as quais foram submetidas a rodízio periódico para evitar algum efeito de localização na casa de vegetação. A adubação foi feita através da aplicação de soluções preparadas para atingir as doses de N, P e $\mathrm{K}$ estipuladas para cada tratamento. As fontes de 
nutrientes foram $\mathrm{NH}_{4} \mathrm{NO}_{3}, \mathrm{NH}_{4} \mathrm{H}_{2} \mathrm{PO}_{4}, \mathrm{NaH}_{2} \mathrm{PO}_{4}, \mathrm{KNO}_{3}$, $\mathrm{KCl} \mathrm{e} \mathrm{KH}_{2} \mathrm{PO}_{4}$. Adicionaram-se, ainda, $30 \mathrm{mg}$ de $\mathrm{S} \mathrm{kg}^{-1}$ de solo, através de $\mathrm{Na}_{2} \mathrm{SO}_{4}$, necessários ao suprimento desse nutriente às plantas, segundo sugerido por NICOLOSO et al. (1999).

Irrigações diárias foram efetuadas com água deionizada, procurando-se manter a umidade do solo entre 40 e $60 \%$ da capacidade de campo, por meio de aferições por pesagem.

No término do experimento, aos 140 dias após a emergência das plantas, foram avaliados os teores de N, P, K, Ca, Mg, Cu, Zn, Fe e Mn nos tecidos da planta, segundo metodologia descrita por TEDESCO et al. (1995).

Foi realizada a análise de variância e, em seguida, quando a interação tripla foi significativa, em nível de 5\% de probabilidade de erro, ajustaram-se superfícies de resposta para as combinações de dois fatores. Para as interações duplas significativas, procedeu-se ao ajuste de superfície de resposta. Já para os efeitos principais, quando as interações não foram significativas, desdobrou-se a soma dos quadrados dos tratamentos em polinômios de $1^{\circ}$ e $2^{\underline{0}}$ graus, ajustando o polinômio de maior grau significativo em nível de 5\% de probabilidade de erro.

\section{RESULTADOS E DISCUSSÃO}

No trabalho anterior (NICOLOSO et al., 2001), foi observado que, dentre os vários parâmetros de crescimento avaliados, o número de folhas por planta foi o mais influenciado pelos tratamentos de adubação, com resposta às adubações isoladas de $\mathrm{N}, \mathrm{P}$ e $\mathrm{K}$, bem como à interação das adubações de NP e NK, fato que esteve fortemente correlacionado à produção de biomassa das folhas e, consequentemente, ao total da planta. No presente trabalho, é apresentado os teores de macro e micronutrientes nos tecidos da grápia nas mesmas condições experimentais daquele trabalho.

O teor de $\mathrm{N}$ nas folhas respondeu à interação das adubações de NP, com dose de máxima eficiência técnica estimada (DMET) de, respectivamente, 89 e $73 \mathrm{mg} \mathrm{kg}^{-1}$ (Figura 1a), bem como pela adubação de PK, com DMET de, respectivamente, 58 e $31 \mathrm{mg} \mathrm{kg}^{-1}$ (Figura 1b). O menor teor de $\mathrm{N}$ nas folhas $(1,8$ a $2,3 \%)$ foi observado nos tratamentos sem adubação nitrogenada e no tratamento testemunha; já o maior teor (3,3\%) foi obtido na presença da maior dose de adubação NP. O aumento das adubações de $\mathrm{P}$ e $\mathrm{K}$, quando associadas ao incremento da adubação de $\mathrm{N}$, diminuiu o teor de $\mathrm{N}$ no caule (Figuras 1c e 1d, respectivamente). Quanto ao teor de $\mathrm{N}$ nas raízes, houve apenas efeito isolado da adubação nitrogenada, que induziu aumento linear
(Figura 1e). NICOLOSO et al. (1999) constataram redução no teor de $\mathrm{N}$ nas raízes, no caule e nas folhas de grápia, também cultivada em Argissolo Vermelho distrófico arênico, respectivamente, na ordem de 84\%, $56 \%$ e $24 \%$ pela omissão de $\mathrm{N}$ na adubação. Esse fato comprova a deficiência deste solo $(0,7 \%$ de matéria orgânica) em suprir $\mathrm{N}$ para o máximo crescimento de plantas jovens de grápia.

Valores semelhantes no teor de $\mathrm{N}$ registrados para a grápia no presente trabalho também foram observados em outras espécies arbóreas, sob condições experimentais diversas, tais como Ilex paraguariensis, por REISSMANN \& PREVEDELLO (1992), em Croton urucurana, Croton floribundus e Trema micrantha, por GONÇALVES et al. (1992), e em Acacia mangium, tibouchina granulosa, Platycymus regnellii e Aspidosperma polyneuron, por BRAGA et al.(1995).

O acúmulo de $\mathrm{N}$ nas raízes, no caule e nas folhas respondeu à adubação isolada de $\mathrm{P}$, aumentando conforme a disponibilidade de $P$ pela adubação (Figura 1f). Também houve efeito de interação tripla das adubações NPK para o acúmulo de N nas folhas, com DMET acima das maiores doses utilizadas.

$\mathrm{O}$ teor de $\mathrm{P}$ na folha respondeu à interação das adubações de PK, com DMET de, respectivamente, 80 e $40 \mathrm{mg} \mathrm{kg}^{-1}$ (Figura 2a). Nos tratamentos sem adubação fosfatada e testemunha, o teor de $P$ nas folhas variou entre 0,06 a 0,09\%. Já na presença de 40 e $80 \mathrm{mg}$ de $\mathrm{P} \mathrm{kg}^{-1}$, estes valores foram entre 0,08 a $0,19 \%$, com incremento de $100 \%$ na presença da dose máxima de P. Trabalhando com a mesma espécie e solo, NICOLOSO et al. (1999) registraram redução de $72 \%$ no teor de $P$ foliar pela omissão de $\mathrm{P}$ na adubação. $\mathrm{O}$ teor de $\mathrm{P}$ no caule apenas respondeu à adubação isolada de $\mathrm{P}$, aumentando linearmente (Figura 2b). Já o teor de P nas raízes apresentou resposta às interações da adubação NP e PK, com DMET de 80 e $40 \mathrm{mg} \mathrm{kg}^{-1}$, respectivamente para $\mathrm{PeN}$ (Figura 2c), e 80 e 20 $\mathrm{mg} \mathrm{kg}^{-1}$, respectivamente para P e K (Figura 2d). O incremento no teor de P (100\%) nas raízes, pela utilização da maior dose de adubação fosfatada, foi semelhante àquele observado no caule. Os valores do teor de $\mathrm{P}$ no caule e raízes da grápia, observados no presente trabalho e por NICOLOSO et al. (1999), são muito baixos se comparados àqueles constatados para outras espécies arbóreas tropicais, tais como Croton urucurana, Croton floribundus e Trema micrantha (GONÇALVES et al., 1992), fato que demonstra a variação genotípica entre as espécies quanto às suas capacidades de absorção e eficiência no uso desse nutriente (RESENDE et al., 2000; LUCA et al. ,2002). Em trabalho recente com espécies arbóreas, PAOLI et al. (2005) observaram que a maior eficiência 
(a)

$\mathrm{N}$ folha $=2,24+0,012 \mathrm{~N}-0,0001 \mathrm{~N}^{2}+0,004 \mathrm{P}-0,000076 \mathrm{P}^{2}+0,000082 \mathrm{NP}$ $\left(\mathrm{R}^{2}=0,71\right)$

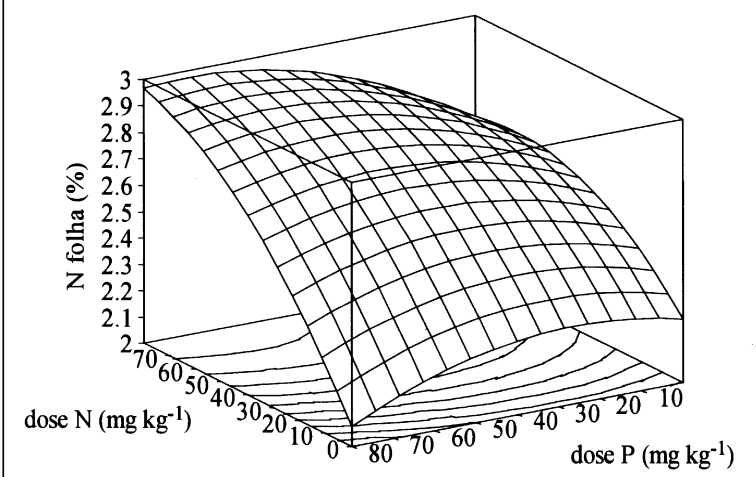

(c)

$\mathrm{N}$ caule $=0,92+0,0013 \mathrm{~N}+0,0001 \mathrm{~N}^{2}+0,000018 \mathrm{P}-0,000024 \mathrm{P}^{2}-0,000024 \mathrm{NP}$ $\left(\mathrm{R}^{2}=0,68\right)$

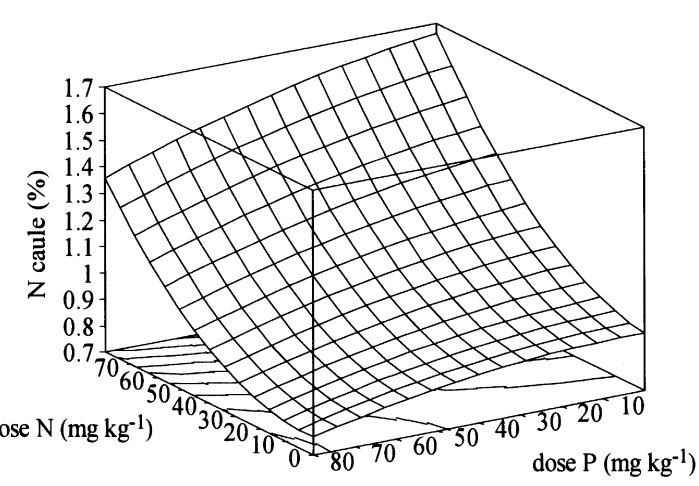

(e)

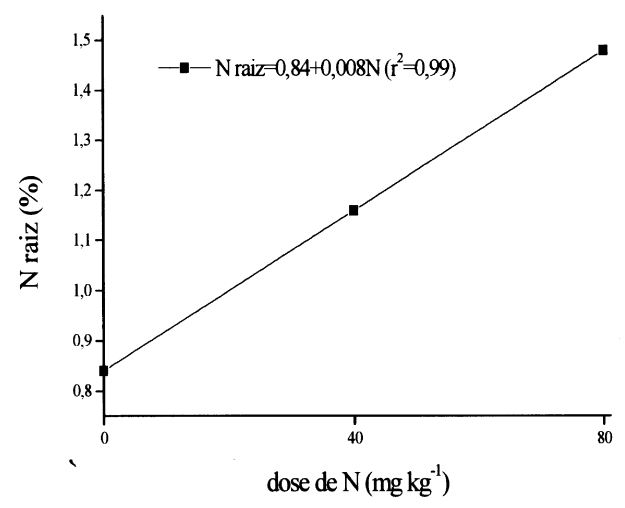

(b)

$\mathrm{N}$ folha $=2,041+0,015 \mathrm{P}-0,000086 \mathrm{P}^{2}+0,012 \mathrm{~K}-0,000043 \mathrm{~K}^{2}-0,00016 \mathrm{PK}$ $\left(\mathrm{R}^{2}=0,58\right)$

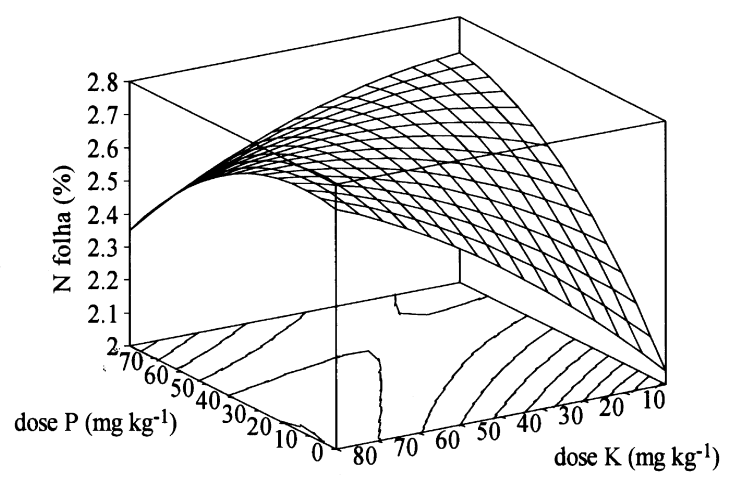

(d) $\mathrm{N}$ caule $=0,78+0,0028 \mathrm{~N}+0,0001 \mathrm{~N}^{2}+0,0019 \mathrm{~K}+0,0000042 \mathrm{~K}^{2}-0,000073 \mathrm{NK}$
$\left(\mathrm{R}^{2}=0,93\right)$

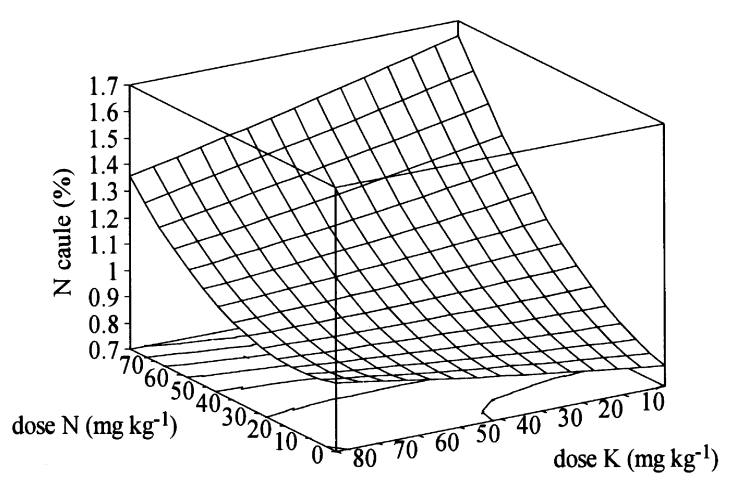

(f)

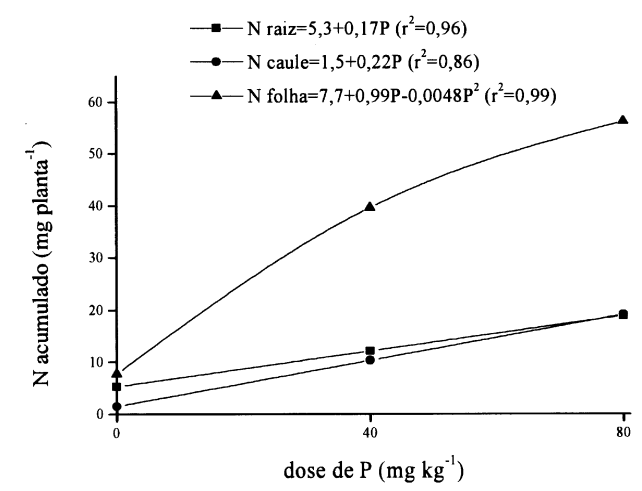

Figura 1 - Efeito da adubação de N, P e K, aplicada isoladamente ou em conjunto, no teor de N da folha (a, b), do caule (c, d) e da raiz (e), bem como no $\mathrm{N}$ acumulado (f) em plantas de grápia aos 140 dias após a emergência. 


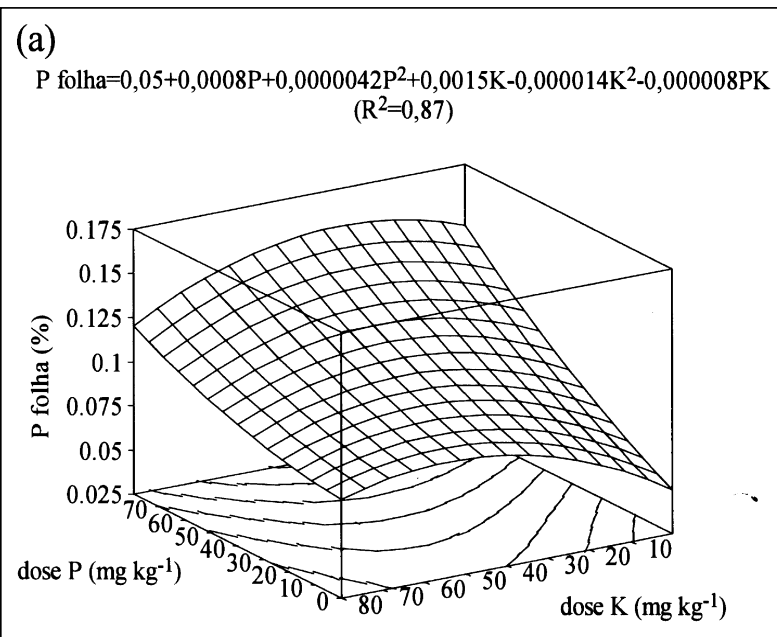

(c)

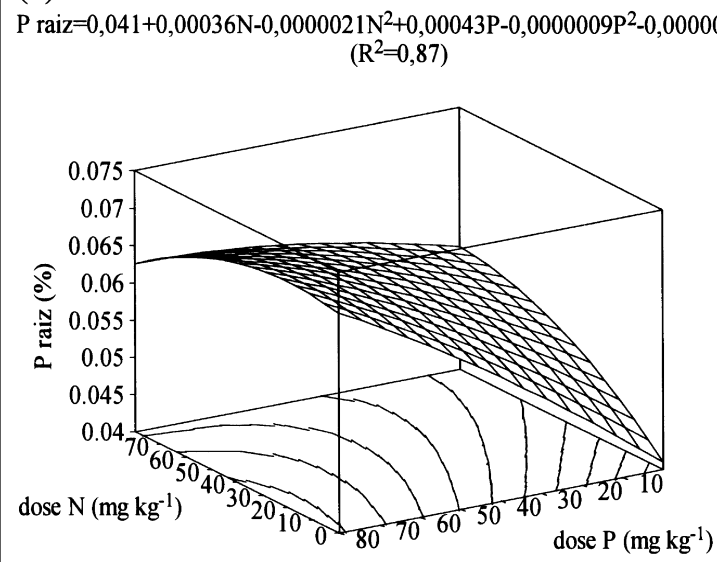

(e)

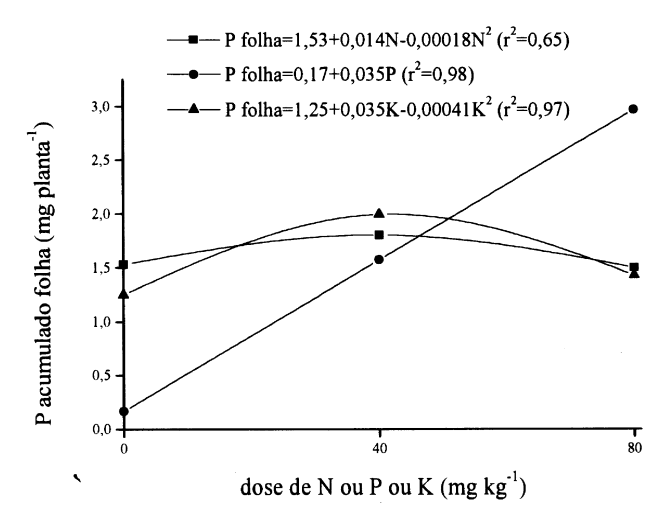

(b)

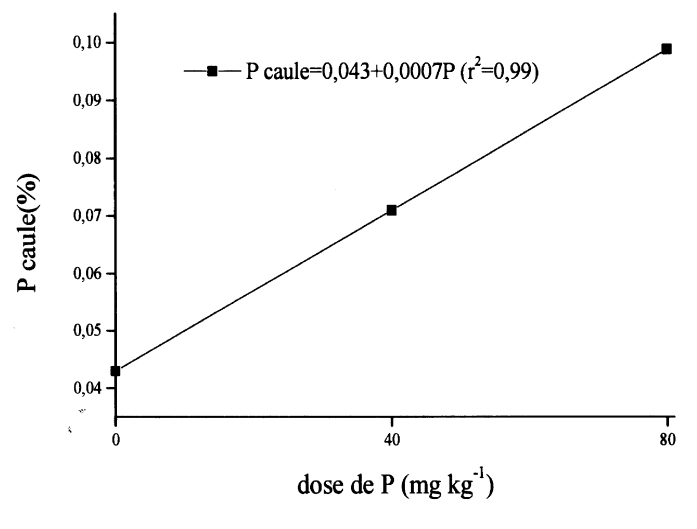

(d)

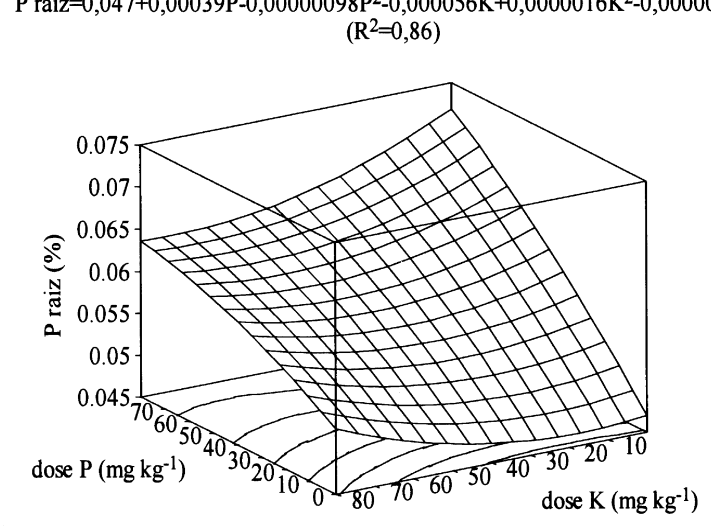

(f)

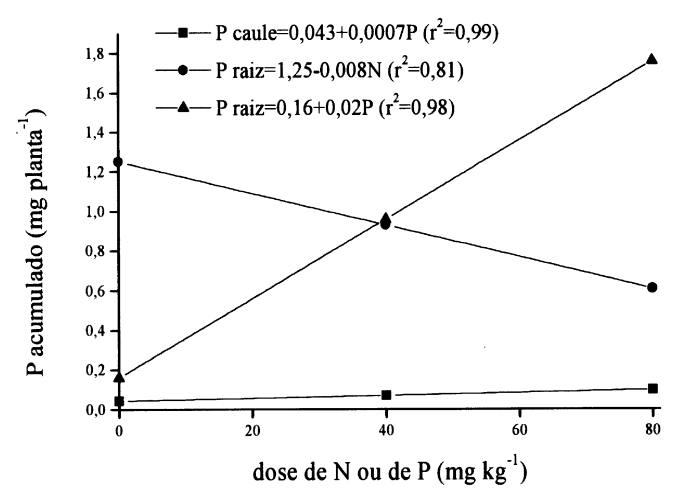

Figura 2 - Efeito da adubação de N, P e K aplicada isoladamente ou em conjunto, no teor de P da folha (a), do caule (b) e da raiz (c, d), bem como no P acumulado na folha (e), no caule e nas raízes (f), em plantas de grápia aos 140 dias após a emergência. 
de absorção e de uso do P com o declínio do P do solo aumentaram acima das expectativas a produtividade das plantas em solos pobres em P, tendo, conseqüentemente, tendo drástica influência nos padrões de produção de biomassa da parte aérea das plantas e de suas distribuições no ambiente.

$\mathrm{O}$ acúmulo de $\mathrm{P}$ nas folhas aumentou linearmente à aplicação isolada da adubação fosfatada e quadraticamente às adubações isoladas de $\mathrm{N}$ e $\mathrm{K}$, com DMET de 40 $\mathrm{mg} \mathrm{kg}^{-1}$ (Figura 2e). Para o acúmulo de $\mathrm{P}$ no caule, houve resposta linear positiva à adubação de $\mathrm{P}$ (Figura 2f). Já nas raízes verificou-se resposta linear positiva à aplicação isolada de $\mathrm{P}$ e linear negativa ao $\mathrm{N}$ (Figura 2f). Além disso, para o $\mathrm{P}$ acumulado nas raízes, houve resposta à interação tripla da adubação NPK, com DMET de 80, 80 e 40mg kg-1, respectivamente ao $\mathrm{N}, \mathrm{P}$ e $\mathrm{K}$.

Não se observou efeito de diluição no teor de $\mathrm{N}$ nos tecidos da grápia em função dos tratamentos de adubação usados. Na presença de adubação fosfatada, constatou-se aumento expressivo no crescimento de plantas e, conseqüentemente, elevação da taxa de absorção de nutrientes, dentre eles o $\mathrm{N}$. Portanto, conclui-se, pelos dados apresentados aqui, bem como por aqueles de NICOLOSO et al. (1999), que o P foi o macronutriente mais limitante ao crescimento da grápia cultivada em Argissolo Vermelho distrófico arênico.

O teor de $\mathrm{K}$ nos tecidos da grápia apenas respondeu à aplicação isolada das adubações N e K. Nas raízes, caule e folhas, o teor de $\mathrm{K}$ aumentou linearmente pela adubação potássica (Figura 3a). Enquanto isso, a aplicação isolada de $\mathrm{N}$ aumentou o teor de K no caule (Figura 3a). Nas folhas, o teor de K variou entre 1,1 a $1,4 \%$ para os tratamentos sem adubação potássica e na testemunha, e entre 1,4 a 2,1\%

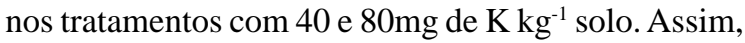
esses teores observados na presença de adubação potássica estão dentro da faixa de valores considerados adequados para o máximo crescimento de plantas jovens de grápia (NICOLOSO et al., 1999) e também de outras espécies florestais (REISSMANN \& PREVEDELLO, 1992; GONÇALVES et al., 1992; MALAVOLTA et al., 1997). Além disso, nos tratamentos sem adubação potássica, houve uma limitação marcante no crescimento das plantas (NICOLOSO et al., 2001), fato que indica que o teor original de $\mathrm{K}$ no solo (16mg L ${ }^{-1}$ ) é insuficiente para proporcionar um desempenho satisfatório para o desenvolvimento dessa espécie.

$\mathrm{O}$ acúmulo de $\mathrm{K}$ nas folhas respondeu à interação das adubações de NK, PK e NPK, sendo que as DMET foram de $80 \mathrm{mg} \mathrm{kg}^{-1}$ (Figuras 3b, 3c). Para o acúmulo de $\mathrm{K}$ no caule, verificou-se apenas efeito isolado das adubações de $\mathrm{P}$ e $\mathrm{K}$, com aumento linear (Figura 3d). Já para o acúmulo de K nas raízes, houve efeito isolado da adubação fosfatada (Figura 3d) e efeito de interação das adubações NK (Figura 3e), ambas com DMET na maior dose utilizada.

O teor de Ca nas folhas, no caule e nas raízes, respectivamente $0,61 \%, 0,32 \%$ e $0,22 \%$, não foi influenciado pelos tratamentos de adubação. Por outro lado, o teor de Mg nas folhas diminuiu pela aplicação isolada da adubação fosfatada e potássica, na ordem de $7 \%$ e $30 \%$, respectivamente (Figura $4 a$ ). Os teores de Ca e Mg no solo, respectivamente 1,0 e 0,6Cmol $\mathrm{L}^{-1}$, embora abaixo dos teores mínimos críticos recomendados para os solos do Rio Grande do Sul e de Santa Catarina (CQFS-RS/SC, 2004), aparentemente não afetaram o crescimento da grápia, a qual apresentou como teor médio nas folhas $0,61 \%$ e $0,23 \%$, respectivamente para $\mathrm{Ca}$ e $\mathrm{Mg}$, valores considerados adequados para espécies lenhosas de rápido crescimento, tais como Eucalyptus e Pinus (GONÇALVES, 1988). Também em grápia cultivada em Argissolo Vermelho distrófico arênico, NICOLOSO et al. (1999) constataram ausência de resposta à adubação de Ca e Mg. Utilizando condições experimentais similares às usadas nos estudos com grápia, outros autores também têm observado ausência de resposta à adubação de Ca e Mg, tais como em Acacia mangium e Aspidosperma polyneuron (peroba-rosa) por BRAGA et al. (1995), em Hymenaea courbaril (jatobá) por DUBOC et al. (1996). Portanto, nas condições de solo ácido $(\mathrm{pH}=4,8)$ em que foi desenvolvido o presente estudo, conclui-se que a grápia é uma espécie eficiente na absorção e na utilização de Ca e Mg. Recentemente, FORTUNATO \& NICOLOSO (2004) demonstraram que plântulas de grápia são tolerantes ao $\mathrm{Al}^{3+}$ em condições de alta acidez do substrato por apresentarem a habilidade de elevar o $\mathrm{pH}$ da rizosfera.

Os teores de $\mathrm{Zn}$ e $\mathrm{Cu}$ nos tecidos de folhas, do caule e das raízes não foram alterados pelas adubações NPK. Por outro lado, o teor de Mn nas folhas respondeu à interação das adubações NK (Figura 4b), PK (Figura 4c) e NPK, com DMET nas maiores doses utilizadas. Já o teor de Fe apresentou apenas efeito isolado às adubações de $\mathrm{N}$ e $\mathrm{P}$ nos tecidos do caule, apresentando diminuição em torno de $42 \%$ nas doses de $80 \mathrm{mg} \mathrm{kg}^{-1}$ (Figura 4d). Os teores foliares de $\mathrm{Cu}, \mathrm{Zn}$, Fe e Mn (média de todos tratamentos), respectivamente de 2,4, 61, 127 e 314mg kg-1 matéria seca, parecem refletir uma condição de suficiência de sua disponibilidade no solo (Mn=10,6mg L-1; $\mathrm{Zn}=1,6 \mathrm{mg} \mathrm{L}^{-1}$; $\mathrm{Cu}=0,9 \mathrm{mg} \mathrm{L}^{-1}$; $\mathrm{Fe}=41,3 m g \mathrm{~L}^{-1}$ ), já que, em $\mathrm{pH}$ baixo $(4,8)$, condição 
(a)

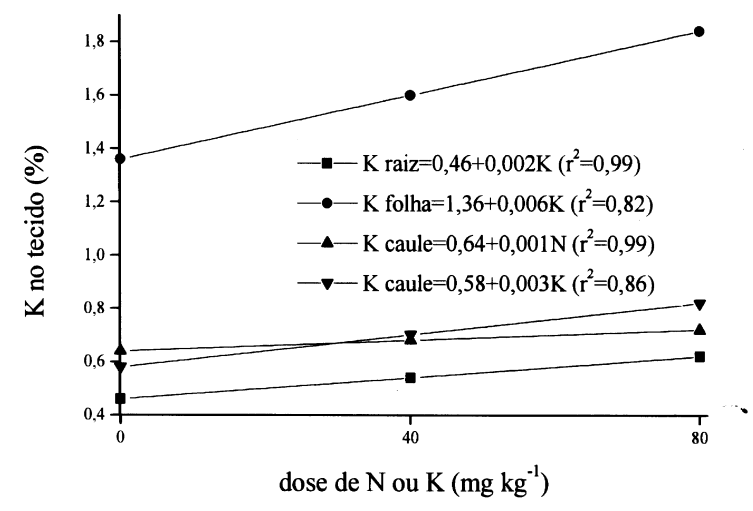

(c)

\section{$\mathrm{K}$ folha $=3,3+0,38 \mathrm{P}-0,0011 \mathrm{P}^{2}+0,18 \mathrm{~K}-0,0023 \mathrm{~K}^{2}+0,0031 \mathrm{PK}$} $\left(\mathrm{R}^{2}=0,83\right)$

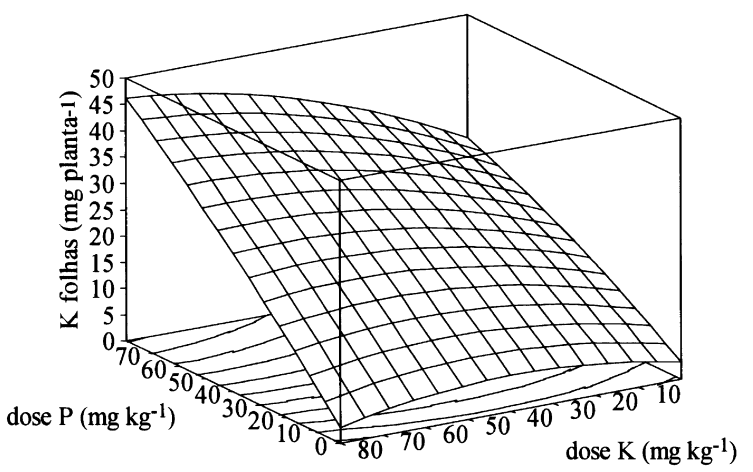

(b)

$\mathrm{K}$ folha $=16,15-0,031 \mathrm{~N}-0,000017 \mathrm{~N}^{2}+0,17 \mathrm{~K}-0,0017 \mathrm{~K}^{2}+0,0026 \mathrm{NK}$ $\left(\mathrm{R}^{2}=0,77\right)$

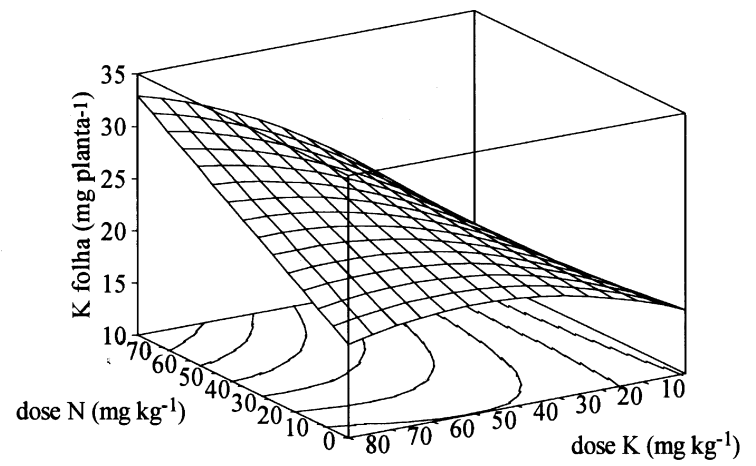

(d)

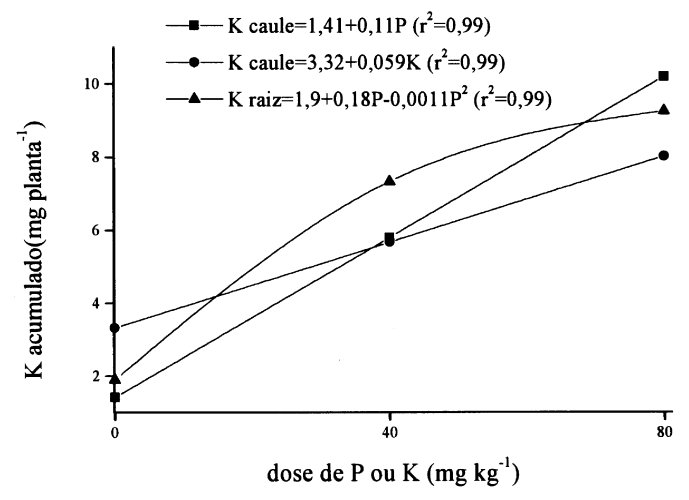

(e)

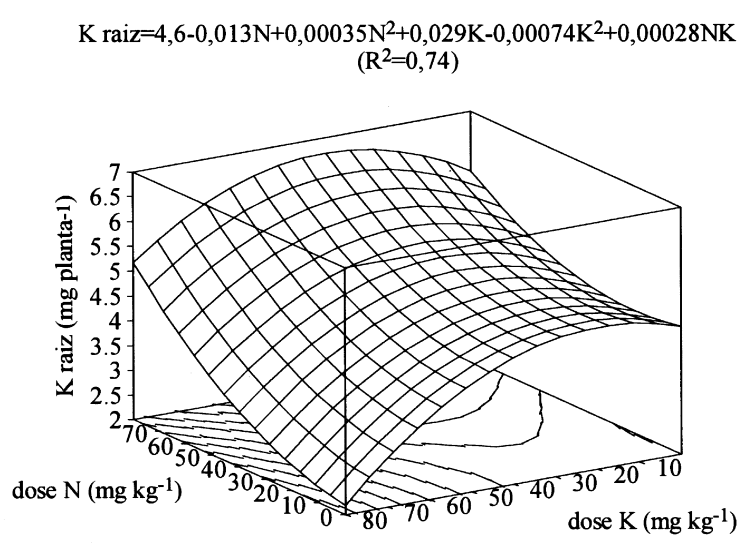

Figura 3 - Efeito da adubação de N, P e K, aplicada isoladamente ou em conjunto, no teor de K da folha, do caule e das raízes (a), bem como no K acumulado na folha (b, c), no caule (d) e nas raízes (d, e), em plantas de grápia aos 140 dias após a emergência. 
(a)

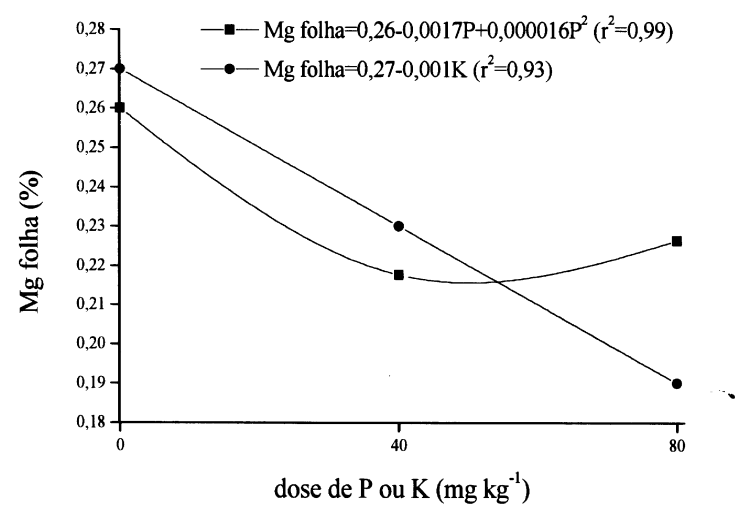

(c)

Mn folha $=3,27+0,38 \mathrm{P}-0,0011 \mathrm{P}^{2}+0,18 \mathrm{~K}-0,0023 \mathrm{~K}^{2}+0,031 \mathrm{PK}$ $\left(R^{2}=0,98\right)$

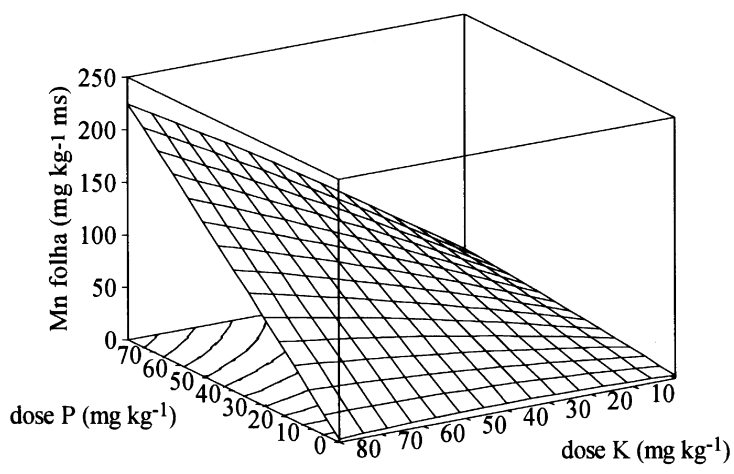

(b)

Mn folha $=16,15-0,031 \mathrm{~N}-0,000017 \mathrm{~N}^{2}+0,18 \mathrm{~K}-0,0017 \mathrm{~K}^{2}+0,026 \mathrm{NK}$ $\left(\mathrm{R}^{2}=0,77\right)$

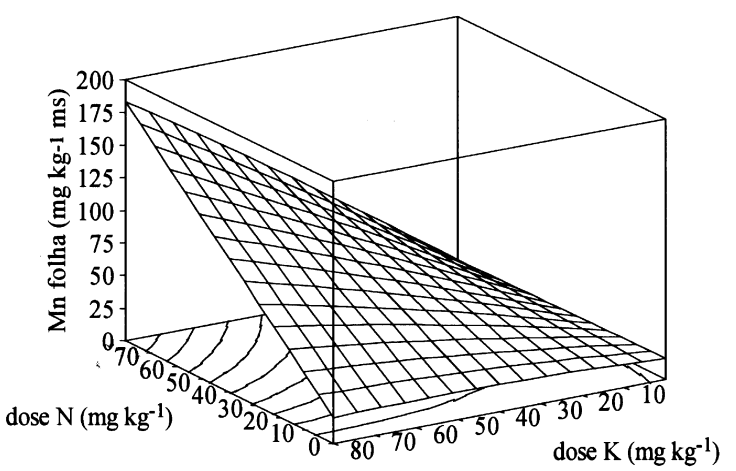

(d)

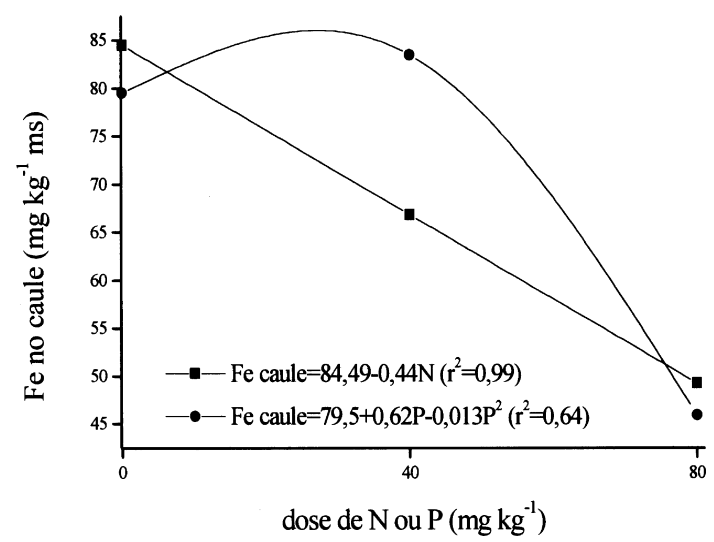

Figura 4 - Efeito da adubação de N, P e K, aplicada isoladamente ou em conjunto, no teor de Mg da folha (a), no teor de Mn da folha (b, c) e no teor de Fe do caule (d), em plantas de grápia aos 140 dias após a emergência.

natural do Argissolo Vermelho distrófico arênico, a disponibilidade desses micronutrientes é a mais alta, facilitando a absorção pelas plantas. Trabalhando com a mesma espécie e o mesmo solo, NICOLOSO et al. (1999) observaram teores muito similares para esses nutrientes, com exceção no teor de Fe, que foi o dobro nas folhas, porém semelhantes no caule e nas raízes.

Similarmente ao registrado por NICOLOSO et al. (1999), verificou-se que os teores de $\mathrm{Cu}$, Zn e Fe foram maiores nas raízes, sendo, respectivamente, 54\%, $97 \%$ e $215 \%$ superiores àqueles encontrados nas folhas. Por outro lado, o maior teor de Mn foi encontrado nas folhas, sendo $330 \%$ maior ao encontrado nas raízes. NICOLOSO et al. (1999), utilizando a técnica do nutriente faltante, constataram que a omissão dos micronutrientes $\mathrm{Cu}, \mathrm{Zn}$, Fe e Mn da adubação não afetou o crescimento da grápia, bem como a concentração desses nutrientes nos tecidos da planta, demonstrando que os teores naturais desses elementos no solo são adequados.

Levando-se em consideração a produção de biomassa total da planta (NICOLOSO et al., 2001), a qual apresentou resposta à adubação fosfatada e potássica, com DMET acima de $80 \mathrm{mg} \mathrm{kg}^{-1}$, e à adubação nitrogenada, com DMET de $70 \mathrm{mg} \mathrm{kg}^{-1}$, os dados do presente trabalho sugerem que os teores adequados de nutrientes nas folhas da grápia, para se obter de 80 a $100 \%$ da matéria seca, sejam: $\mathrm{N}=2,5$ a 3,0\%; $\mathrm{P}=0,1$ a $0,18 \%, \mathrm{~K}=1,6$ a 2,1\%, $\mathrm{Ca}=0,60$ a 0,75\%, $\mathrm{Mg}=0,2$ a $0,3 \%$; $\mathrm{Cu}=1,5$ a 2,5 $\mathrm{mg} \mathrm{kg}^{-1}, \mathrm{Zn}=50$ a $85 \mathrm{mg} \mathrm{kg}^{-1}, \mathrm{Fe}=100$ a $150 \mathrm{mg}$ $\mathrm{kg}^{-1}$ e $\mathrm{Mn}=250$ a $400 \mathrm{mg} \mathrm{kg}^{-1}$.

\section{REFERÊNCIAS}

BRAGA, F.A.M. et al. Exigência nutricional de quatro espécies florestais. Revista Árvore, Viçosa, v.19, n.1, p.18-31, 1995.

Ciência Rural, v.37, n.2, mar-abr, 2007. 
COMISSÃO DE QUÍMICA E FERTILIDADE DO SOLO - RS/ SC. Manual de adubação e calagem para os estados do Rio Grande do Sul e Santa Catarina. Porto Alegre: SBCSNRS, 2004. 400p.

DUBOC, E. et al. Nutrição do jatobá (Hymenaea courbaril L. var.stilbocarpa (Hayne) Lee et Lang.). Cerne, Lavras, v.2, n.2, p.243-244, 1996.

FORTUNATO, R.P.; NICOLOSO, F.T. Toxidez de alumínio em plântulas de grápia (Apuleia leiocarpa Vog. Macbride). Ciência Rural, Santa Maria, v.34, n.1, p.89-95, 2004.

GONÇALVES, J.L.M. Propriedades físico-químicas dos solos vs. exigências nutricionais de espécies florestais de rápido crescimento. Piracicaba: IPEF, 1988. 11p. (Circular técnica 154).

GONÇALVES, J.L.M. et al. Capacidade de absorção e eficiência nutricional de algumas espécies arbóreas tropicais. In: CONGRESSO NACIONAL SOBRE ESSÊNCIAS NATIVAS, 2. , 1992, São Paulo, SP. Anais... São Paulo: Instituto Florestal, 1992. p.463-468.

LUCA, E.F. de et al. Eficiência de absorção e utilização de fósforo $\left({ }^{32} \mathrm{P}\right)$ por mudas de eucalipto e arroz. Scientia Agrícola, Piracicaba, v.59, n.3, p.543-547, 2002.

MALAVOLTA, E. et al. Avaliação do estado nutricional das plantas, princípios e aplicações. Piracicaba: Associação Brasileira para Pesquisa da Potassa e do Fosfato. 1997. 319p.

MARSCHNER, H. Mineral nutrition of higher plants. London: Academic, 1995. 890p.

MISSIO, E.L. et al. Exigências nutricionais da grápia ao fósforo e enxofre em Argissolo Vermelho distrófico arênico: efeito da adubação no crescimento. Ciência Rural, Santa Maria, v.34, v.4, p.1051-1057, 2004.

MISSIO, E.L.; NICOLOSO, F.T. Distúrbios nutricionais induzidos pela adubação de fósforo e ferro em plantas jovens de grápia (Apuleia leiocarpa). Ciência Florestal, Santa Maria, v.15, n.4, p.377-389, 2005.

NICOLOSO, F.T. et al. Efeito de métodos de escarificação na superação da dormência de sementes e dois substratos na germinação e no desenvolvimento da grápia (Apuleia leiocarpa). Ciência Rural, Santa Maria, v.27, n.3, p.419-424, 1997.

NICOLOSO, F.T. et al. Exigências nutricionais da grápia (Apuleia leiocarpa Vog. Macbride) em solo Podzólico vermelho amarelo. Ciência Rural, Santa Maria, v.29, n.2, p.225-231, 1999.
NICOLOSO, F.T. et al. Nutrição mineral de mudas de grápia em argissolo vermelho distrófico arênico: (I) Efeito da adubação NPK no crescimento. Ciência Rural, Santa Maria, v.31, n.6, p.991-998, 2001.

NICOLOSO, F.T. et al. Fontes de nitrogênio mineral (N-NO e $\mathrm{N}-\mathrm{NH}^{+}$) no crescimento de mudas de grápia (Apuleia leiocarpä (Vog.) Macbride). Ciência Florestal, Santa Maria, v.15, n.3, p.221-231, 2005.

NOVAIS, R.F. et al. Nutrição mineral do eucalipto. In: BARROS, N.F.; NOVAIS, R.F. Relação solo-eucalipto. Viçosa: Editora Folha de Viçosa, 1990. Cap.2, p.25-98.

PAOLI, G.D. et al. Phosphorus efficiency of bornean rain forest productivity: evidence against the unimodal efficiency hypothesis. Ecology, New York, v.86, n.6, p.1548-1561, 2005.

PRESOTTI, L.C. Nível crítico de potássio no solo para a produção de mudas de eucalipto. 1985. 45f. Dissertação (Mestrado e Agronomia) - Programa de Pós-graduação em Agronomia, Universidade Federal de Viçosa.

REITZ, R. et al. Projeto madeira do Rio Grande do Sul. Porto Alegre: CORAG, 1988. 525p.

REISSMANN, C.B.; PREVEDELLO, B.M.R. Influência da calagem no crescimento e na composição química foliar da erva-mate (Ilex paraguariensis St.Hil.). In: CONGRESSO NACIONAL SOBRE ESSÊNCIAS NATIVAS, 2., 1992, São Paulo. Anais... São Paulo: Instituto Florestal, 1992. p.625629.

RESENDE, A.V. de et al. Acúmulo e eficiência nutricional de macronutrientes por espécies florestais de diferentes grupos sucessionais em resposta à fertilização fosfatada. Ciência e Agrotecnologia, Lavras, v.24, n.1, p.160-173, 2000.

RIZZINI, C.T. Árvores e madeiras úteis do Brasil. Manual de dendrologia brasileira. São Paulo: Universidade Federal de São Paulo, 1971. 294p.

SÁNCHEZ P.A.; SALINAS, J.G. Low-input technology for managing oxisols and ultisols in tropical América. Advances in Agronomy, New York, v.34, p.279-406, 1981.

SEMA. Espécies da flora ameaçadas de extinção do Rio Grande do Sul. Capturado em 6 mar. 2006. Online. Disponível na Internet http://www.sema.res.gov.br/sema/html/ especies-ameacadas.pdf.

TEDESCO, M.S. et al. Análise de solo, plantas e outros materiais. Porto Alegre: Universidade Federal do Rio Grande do Sul, 1995. 174p. (Boletim técnico 5). 